1. Group : Synthesis of Iso-quinoline-Derivatives. Paperes hitherto been published:-

1. S. Sugasawa and H. Yoshikawa: Synthesis of Laudanosoline and its Dehydrogenation. (Soc. 1933, 1583)

2. S. Sugasawa: Synthesis of $1-\left(3^{\prime}, 4^{\prime}, 5^{\prime}\right.$-Trimethoxyphenyl)-6, 7-diethoxyisoquinoline. [J. Pharm. Soc. Jap. 55, 224, (1935)]

3. S. Sugasawa and T. Tsuda : Some Experiments upon the Synthesis of Papaverine. [J. Pharm. Soc. Jap. 55, 1044, (1935)]

4. S. Sugasawa and K. Kakemi: Synthesis of 1-( $3^{\prime}, 4^{\prime}, 5^{\prime}-$ Trimethoxyphenyl $)-6-$ propyloxy-7-methoxy-isoquinoline. [J. Pharm. Soc. Jap. 55, 1283, (1935)]

5. S. Sugasawa and K. Sakurai: Synthesis of 1-(3',4'-Methylenedioxybenzyl)-3methylenedioxyisoquinoline. [J. Pharm. Soc. Jap. 56, 563, (1936)]

6. S. Sugasawa and M. Kuriyagawa : Synthesis of Pyridyl-isoquinolinederivatives (Preriminary Report). [Ber. 69, 2068, (1936)]

7. S. Sugasawa and K. Kakemi: Synthesis of some 3-Methylisoquinolines. [J. Pharm. Soc. Jap. 57, 173, (1937)]

2. Group: Synthesis of Quinoline-Derivatives.

3. Group: Synthesis of Indol-Derivatives.

4. Group: Synthesis of Condensed Nitrogen-Ring-Compounds.

\title{
Studies on the Synthesis of Nitrogen-Ring-Compounds (VIII.)
}

\section{Group: Synthesis of Quinoline-Derivatives. (I.)}

\section{A New Synthesis of Quinoline.}

\author{
by \\ Shigehiko Sugasawa and Kiitiro KAKEMI \\ [From the Pharm. Instit. of the Imperial Univ. of Tokyo] \\ (Received July 12 th. 1937)
}

With regard to our investigation concerning pyridocoline-derivatives, 6, 7-dimethoxyquinoline was needed, of which nothing paticular is given in the literature. One of the present authors (S. S) tried to synthesize this compound in vain from 3,4-dimethoxy- 
aniline by means of Skraup-method under various conditions; no definite substance being obtained. 6,7-Ethylenedioxyquinoline, which can be prepared from 3, 4-ethylenedioxyaniline by usual Skraup-method without difficulty, is so resistent toward hydrolysis, that the substitution of ethylenedioxy-group by two methoxy-groups was unsuccessful.

According to K. Kindler [A. 431, 187, (1923)], acid-amides, when treated with $\mathrm{P}_{2} \mathrm{~S}_{5}$ and $\mathrm{K}_{2} \mathrm{~S}$ in xylene solution, give rise to the corresponding thioamides, which afford amines with same $\mathrm{C}$-number on reduction:

$$
\mathrm{R} \cdot \mathrm{CONH}_{2} \longrightarrow \mathrm{R} \cdot \mathrm{CSNH}_{2} \longrightarrow \mathrm{R} \cdot \mathrm{CH}_{2} \mathrm{NH}_{2}
$$

Ruzicka was the first [Helv. 16, 1323, (1933); ibid. 18, 659, (1935)] to apply this method upon lactams and succeeded in preparing polymethyleneimines:

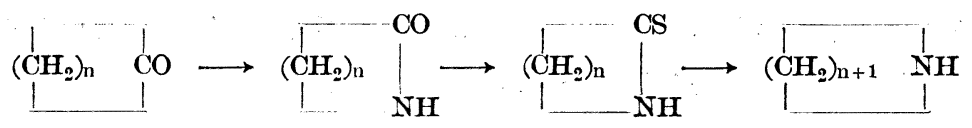

If the above reactions can be applied upon $a$-hydrindone, py-tetrahydroquinoline will be prepared, and this was really the case. Since tetrahydroquinoline ean easily be dehydrogenated to quinoline by the elegant method of S. Akabori [Bull. Chem. Soc. Jap. 4, 198, (1929)], quinoline now became obtainable from cinnamic acid through following series of reactions, where any drastic treatment is absent.

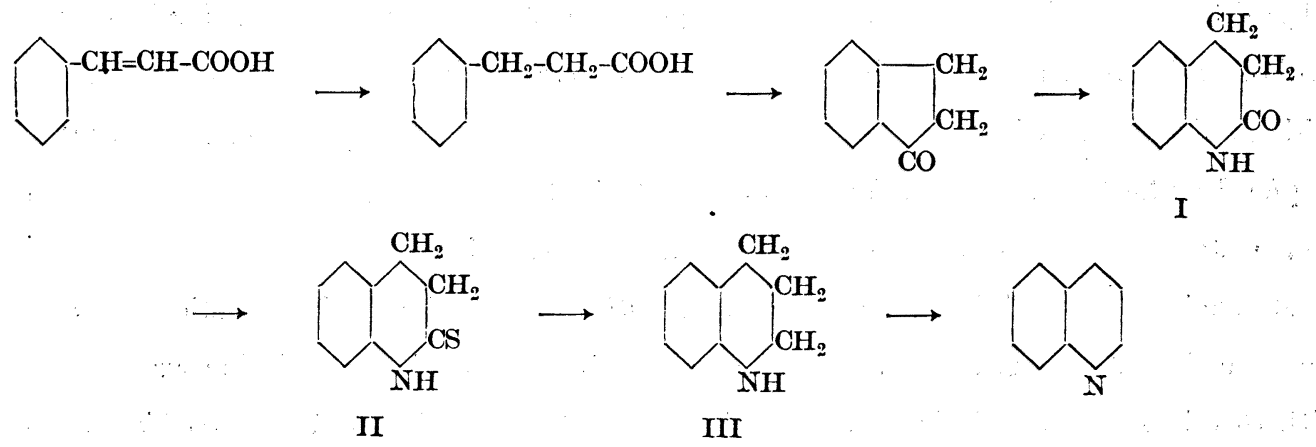

Thus the preparation of 6,7 -dimethoxyquinoline is now feasible and the investigation will be extended to other quinolines, indoles, phenanthridines and various other types of acid amides and lactams.

\section{(Experimental)}

3, 4-Dihydrocarbostyryil (I). Beckmann-rearrangement of a-hydrindoneoxim was 
undertaken under various conditions using variety of reagents for instance, $\mathrm{H}_{2} \mathrm{SO}_{4}$, $\mathrm{POCl}_{3}, \mathrm{PCl}_{3}, \mathrm{PCl}_{5}, \mathrm{SOCl}_{2}$, etc., but without succees. $\mathrm{NaN}_{3}$ in conc. $\mathrm{H}_{2} \mathrm{SO}_{4}$, which was used by L. P. Walls for the preparation of phenanthridon from fluorenone (Soc. 1935, 1405) was also effective in our case; i. e. in converting hydrindone into dihydrocarbostyril. a-Hydrindone (5.9 g) was dissolved in cold conc. $\mathrm{H}_{2} \mathrm{SO}_{4}(40 \mathrm{cc})$ and treated with $\mathrm{NaN}_{3}(4.3 \mathrm{~g})$ in conc. aqueous solution under stirring and cooling. After an hour's stirring the content was poured into ice and kept standing over night, filtered and purified from acetic ester and petrol-ether. Faint yellow rhombic crystall, m. p. 164 ${ }^{\circ}$. Yield $3.6 \mathrm{~g}(55 \%)$.

3, 4-Dihydrothiocarbostyril (II). Foregoing compound (3g) was suspended in absolute xylene $(30 \mathrm{cc})$ and the whole was warmed at $70-80^{\circ}$ on a steambath. An intimate mixture of $\mathrm{P}_{2} \mathrm{~S}_{5}(2,3 \mathrm{~g})$ and $\mathrm{K}_{2} \mathrm{~S}(3.4 \mathrm{~g})$ was added little by little while being stirred. The xylene solution became reddish and after an hour's heating was decanted while hot and the residue was extracted repeatedly with hot xylene. From the combined extract the solvent was removed in vac., and yellowish needles separated was filtered with suction, dissolved in dilute caustic soda, filtered and reprecipitated by $\mathrm{HCl}$. After repeating the purification from dilute alcohol, the compound was obtained in yellowish needles, m. p. $105^{\circ}$. Yield $2 \mathrm{~g}$. $\left(\mathrm{C}_{9} \mathrm{H}_{11} \mathrm{NS}\right.$ requires $\mathrm{N}, 8.5 ; \mathrm{S}, 19.6$; Found, $\mathrm{N}, 8.5 ; \mathrm{S}$, 20.3)

Py-Tetrahydroquinoline (III). The foregoing substance $(3 \mathrm{~g})$ was dissolved in $70 \mathrm{cc}$ alcohol and reduced electrolytically with $\mathrm{Pb}$-cathode in the presence of some mineral acid ( $\mathrm{HCl}$ was used in this case, $\mathrm{H}_{2} \mathrm{SO}_{4}$ will probably give better result). Using 0.07 $\mathrm{amp} / \mathrm{cm}^{2}$ at $25-30^{\circ}$, the reduction was complete in 2 hours. Alcohol was removed in vac, water was added and the solution was treated with ether to remove non-basic substance if present. The filtered aqueous solution was basified with caustic soda and the base liberated was taken up in ether, and dried. The ethereal solution was treated with dried $\mathrm{HCl}$-gas and the hydrochloride of the base precipitated was purified from alcohol and ether, forming colourless needles, m. p. 181 ${ }^{\circ}$, which was not depressed when admixed with authentic tetrahydroquinoline-hydrochloride. Yield $1.8 \mathrm{~g}(60 \%)\left(\mathrm{C}_{9} \mathrm{H}_{12} \mathrm{NCl}\right.$ requires, C, $63.7 ; \mathrm{H}, 7.1 ; \mathrm{N}, 8.3$ : Found, C, $63.5 ; \mathrm{H}, 7.0 ; \mathrm{N}, 7.9$ )

The benzoyl-derivative of the base melted at $76^{\circ}$ and this was also identified with the authentic specimen. $\left(\mathrm{C}_{16} \mathrm{H}_{15} \mathrm{ON}\right.$ requires $\mathrm{N}, 5.9$; Found $\left.\mathrm{N} 6.0\right)$. 


\title{
含空素異性環狀化合體の合成研究 (VIII) \\ 第二類 ヒノリン列化合體の合成研究 (I) \\ ヒノリンの新合成法に就て
}

\author{
菅 澤 重 坴 \\ 掛見喜一郎
}

（昭和 12 年 7 月 12 日受理）

S. Sugasawa: Synthese der N-haltigen Hetero-ringe (VIII)

II. Gruppe. Synthese in der Chinolin-reihe (I)

S. Sugasawa and K. Kakemi: Neue Synthese des Chinolins.

著者等の一人 (菅澤) は其の研究中 6,7-ヂメトキシヒノリンの必要を生じ之れを文獻に求め. ねるに確實なる記載なく依て 3,4-ヂメトキシアニリンを種ふなる條件下に於て Skraup 反應に 附したるに成績體として酸に可溶性のもの極めて微量にてたとへ本物質全部を所求のヒノリン 誘導體又は對應するフェノール監基と假定するも到底研究に必要なる量の 6,7-ヂメトキシヒノ リンを得る事不可能なるの狀態にありき。依て朁知の方法に依り 6,7-エチレンヂオキシヒノリ ンを合成し之れを鹼化して對應するフェノール監基となし之れを適當なる方法にてメチル化し て目的物に到達せんとしたるもェチレンヂオキシ環の抵抗大にして目的を達し得ざりき。

然るに K. Kindler 氏 氏Ann. 431, 187 (1923)]は種々なる酸アミドに $\mathrm{P}_{2} \mathrm{~S}_{5}$ と $\mathrm{K}_{2} \mathrm{~S}$ とを 作用せしめて對應するチオアミドを製し之れを電解還元に附して圓滑にアミンを製し得をる事 を報告せり。即ち一般式にて示せば下式の如し.

$$
\mathrm{R} \cdot \mathrm{CO} \cdot \mathrm{NH}_{2} \rightarrow \mathrm{R} \cdot \mathrm{CS} \cdot \mathrm{NH}_{2} \rightarrow \mathrm{R} \cdot \mathrm{CH}_{2} \cdot \mathrm{NH}_{2}
$$

本反應に於て R.CO.NR'R" 形のものも同梯に對應するアミンを生ずるを以て環狀酸アミド 郎ちラクタム形の化合物に對し本反應を應用し得るや否やを檢せんとして文獻を按ぜしに Ruzicka 及び協力者等 [Helv. 16, 1323 (1933); ibid. 18, 659 (1935)】 は Polymethylenimin の 製法に於てケトンを原料としそれのオキシムの Beckmann 轉位又はケトンに $\mathrm{HN}_{\mathbf{3}}$ を作用し て得らるるイソオキシムを Kindler 氏法依りチオイソオキシムとなし之れを Tafel 氏還元 に附して Polymethylenimin を得をる事を報ぜり. 即ち一般式を以て示せば下式の如し.

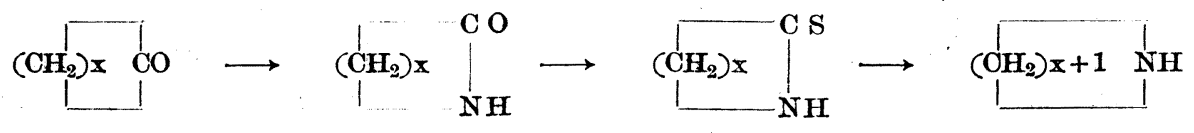


依て本反應をヒドリンドンに應用する事を得れば下式に示す如く比較的穩かなる反應に依り テトラヒドロヒノリンを製し得へく而してテトラヒドロヒノリンは既に 赤堀氏 [Bull. Chem. Snc. Jap. Vol. 4, 198，(1929)] 飞依り圓滑にヒノリンに脫水素化さるる事報ぜられ居るを以て 結局桂皮酸を原料として籣單にヒノリンに到達し得る事となるべし.

先づ常法に依りて製した $3 a$-ヒドリンドンオキシムを種々なる試藥に依り Beckmann 轉位 に附したるも目的物たるとドロカルボスチルを得る事不可能なりき。依て次に $\mathrm{N}_{3} \mathrm{H}$ をいーヒト リンドンに作用せしめをるに圓滑に相當の得量を以てヂヒドロカルボスチリルを得，更に之の ものをキシロール溶液中 $\mathrm{P}_{2} \mathrm{~S}_{5}$ と $\mathrm{K}_{2} \mathrm{~S}$ とを以て所理して對應するチオ化合物を得. 之れを監 酸酒精混液中にて鉛極にて還元したるに容易にテトラヒドロヒノリンを得，一方ヒノリンより 接解還元に依りて製したるテトラヒドロヒノリンと比較して其同一なる事を認め得たり。

此の如く本法に依れば比較的棌かなる條件下にヒノリンを合成し得べきを以て 6,7-ヂメトキ シヒノリンも亦同樣にして製し得へきものと思推し, 目下此の方面の研究站に本反應を 應用し て種そなる合窒化合物例之オキシンドールよりインドール，フルオレノンよりフェナントリヂン 等タの研究を行Uつつあり.

テトラヒドロヒノリン合成徑路を式示すれば下の如し.

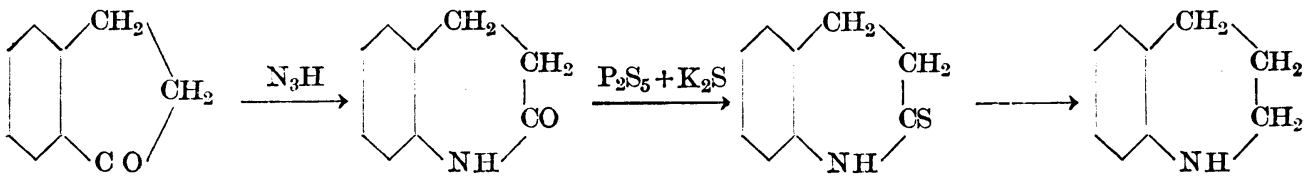

\section{實 驗 之 部}

3,4-Dihydrocarbostyril $\alpha$-Hydrindon (A. 376, 271) $5.9 \mathrm{~g}$ を $40 \mathrm{cc}$ の濃硫酸に溶解せしめ, 外部よ り水水にて冷却しつつ䱋拌下にナトリウムアチド $4.3 \mathrm{~g}$ の濃厚水溶液を一時間牛に互りて滴加す。劇しく

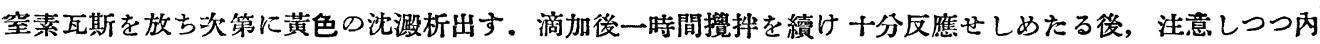
容を水水中に投じ一夜放置して吸引滤過す。これを醋酸エステル，石油エーテルの混液より再結晶して微 黃色稜桂狀晶を得. Fp. $164^{\circ}$ 得量 $3.6 \mathrm{~g}$ (55\%).

3,4-Dihydro-thiocarbostyril 前記 Hydrocarbostyril $3 \mathrm{~g}$ を無水キシロール $30 \mathrm{cc}$ 亿浮遊せしめ水浴 上 70 $80^{\circ} \mathrm{C}$ に保ちつつ, 㨨拌下に五硫化燐 $2.3 \mathrm{~g}$, 硫化加里 $3.4 \mathrm{~g}$ の混合粉末を少量宛加ふ. キシロール 次第に赤色を呈し添加後一時間にして熱時倾鹓し，更に反覆無水キシロールにて抽出し，前後に得たる抽 出液を合し減壓にてキシロールを溜去せば微黃色針狀晶析出す。これを吸引滤過し $10 \%$ の苛性ンーダに溶 解せしめ不溶物質を去り $10 \%$ の監酸にて酸性となし析出ヶしめ, 更にこれを 20 〜 $30 \%$ の稀薄アルコール より再結晶をなすと橫色針狀晶を得. Fp. $105^{\circ}$ 得量 $2 \mathrm{~g}(60 \%)$.

物質 $5.047 \mathrm{mg} \mathrm{N} \mathrm{N}_{2} 0.390 \mathrm{cc}\left(759.1 \mathrm{~mm} 31.2^{\circ}\right)$, 物質 $8.222 \mathrm{mg} \mathrm{BaSO}_{4} 12.166 \mathrm{mg} \mathrm{C}_{9} \mathrm{H}_{11} \mathrm{NS}$ として理論數 $\mathrm{N} \% 8.5 \mathrm{~S} \% 19.6$ 實驗數 $\mathrm{N} \% 8.5 \mathrm{~S} \% 20.3$

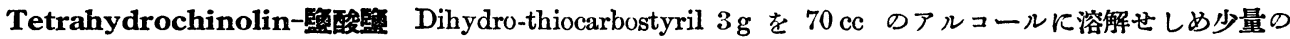
濃監酸を加一，鉿極にて電解還元に附す。一本方センチに就き 0.07 Amp., $25 \sim 35^{\circ} \mathrm{C}$ に保ち 2 時間にて遠 元終了す。減壓にてアルコールを去り水を加へ未反應の原料をェーテルに探りたる後, 液をアルカリ性と 
なし Tetrahydrochinolin を遊唯せしめ, エーテルに探り芒硝にて乾燥す. 滤過後乾燥留酸瓦斯を通導し, 酸監を沈测せしめ,アルコール, エーテルの混液より再結晶を繰り返すに無色長針狀晶を得. Fp. 181 得量 $1.8 \mathrm{~g}$ (60\%) 他方ヒノリンょり T. S. Hamilton, Roger Adams の法 (J. Am. Ch. Soc. 50, 2260, (1928)にて直接 Tetrahydrochinolin-監酸㿼を製し, 混融を行ひしに融點降下せず.

物質 $4.987 \mathrm{mg} \mathrm{CO} 211.602 \mathrm{mg} \quad \mathrm{H}_{2} \mathrm{O} 3.100 \mathrm{mg} \quad \mathrm{C}, 63.45 \% \quad \mathrm{H}, 6.95 \% \quad \mathrm{C}_{9} \mathrm{H}_{12} \mathrm{NCl}$ としての理論值は C, $63.71 \% \mathrm{H}, 7.08 \%$ 物質 $5.092 \mathrm{mg} \mathrm{N}_{2} 3.63 \mathrm{cc}\left(755.7 \mathrm{~mm}, 28.8^{\circ}\right) \mathrm{N} 7.87 \% \mathrm{C}_{9} \mathrm{H}_{12} \mathrm{NCl}$ としての理 論数 $8.26 \%$

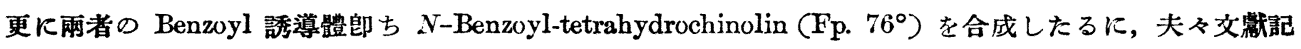
載の融點と一致し兩者を混融するも融點降下せず。

物質 $7.568 \mathrm{mg} \mathrm{N} 20.412 \mathrm{cc}\left(761 \mathrm{~mm} 30.2^{\circ}\right) \mathrm{C}_{16} \mathrm{H}_{15} \mathrm{ON}$ として理論數 $\mathrm{N} \% 5.9$ 實驗數 6.0

\section{2,4,6-トリメチルピリミヂンと ベンツアルデヒドとの縮合（第一報）}

近藤 本三 郎

梁 井 光二

（昭和 12 年 7 月 10 日受理)

Heisaburo Kondo, Mitsuji Yanai: Ueber die Kondensation von 2,4,6-Trimethylpyrimidin und Benzaldehyd. (I. Mitteilung)

ピリヂンの $a$ 位の $\mathrm{CH}_{3}$ 基は次の如く互變異性にして活性を呈するは周知の事實なり．例人 ば $a$ ビコリンはベンツアルデヒドと縮合し、 $a$-Cinnamenylpyridin を成生す。<smiles>Cc1ccccc1</smiles>

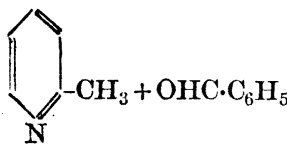

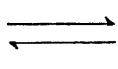<smiles>Cc1ccccc1</smiles>

$\stackrel{\mathrm{ZnCl}_{2}}{\longrightarrow}$

此關係はピリミヂンの空素に隣れる $\mathrm{CH}_{3}$ 基に於ても同樣に推定せらるる處にして種ぬのア ルデヒドと同樣の縮合體成生する事を豫期するを得へし。 